American Journal of Pharmaceutical Education 2020; 84 (10) Article 7889.

\title{
COMMENTARY
}

\section{Update on Pharmacist Workforce Data and Thoughts on How to Manage the Oversupply}

\author{
Lisa Lebovitz, JD ${ }^{\mathrm{a}}$, Mike Rudolph, $\mathrm{PhD}^{\mathrm{b}}$ \\ ${ }^{a}$ University of Maryland School of Pharmacy, Baltimore, Maryland \\ ${ }^{\mathrm{b}}$ University of Kentucky, Lexington, Kentucky \\ Submitted October 17, 2019; accepted May 8, 2020; published October 2020.
}

\begin{abstract}
The annual number of Doctor of Pharmacy (PharmD) graduates is projected to exceed the number of annual pharmacist job openings over the next 10 years. Loss of retail sector jobs will be partially offset by projected gains in several other sectors; however, oversupply will persist until the number of graduates is more reflective of job market capacity. Large-scale practice transformation will not happen overnight; consequently, schools and colleges of pharmacy must immediately change their perspective from producing graduates to fill pharmacist roles, to producing graduates who are prepared with expertise and professional skills to excel in many types of well-paying positions. Students need career advice including to convince potential employers how a PharmD education has prepared them with transferable high-level skills that are applicable beyond traditional pharmacist roles. Better communicating the value of pharmacy skills to students and employers may also have a positive impact on admission numbers as prospective applicants become more aware of the breadth of pharmacy career opportunities.
\end{abstract}

Keywords: workforce, employment, advisors

These are indeed turbulent times for pharmacy with a looming oversupply of highly trained Doctor of Pharmacy (PharmD) graduates vying for mostly traditional dispensing jobs in a quickly contracting marketplace. The need for practice transformation is clear but solutions are not. Strategic changes will take time to shift the profession toward non-distributive functions. Meanwhile, the $14,000+$ PharmD students graduating every year need to find immediate employment.

How did we get here? Perhaps it started with a 2000 conference report from thought leaders who forecasted a need for thousands more non-dispensing pharmacists to improve public health. ${ }^{1}$ This report clearly stated it was not a forecast of demand for pharmacy services and that transformative pharmacy practice was based upon several assumptions. These included establishing a supporting payment mechanism, securing provider status under Medicare, and increasing enrollment in colleges and schools of pharmacy (predicting a very modest $20 \%$ enrollment growth in existing schools and three additional schools). On the latter, thought leaders in 2000 could not have envisioned a $74 \%$ increase in pharmacy programs

Corresponding Author: Lisa Lebovitz, University of Maryland School of Pharmacy, 20 North Pine St., Baltimore, MD 21201. Tel: 410-706-3457. Email: 1lebovitz@rx. umaryland.edu (from 82 in 2000 to 143 in $2018^{3}$ ) and an $81 \%$ increase in total enrollment (from 34,481 in 2000 to 62,504 in 2018). At the same time, accreditation standards evolved to require increased clinical training in PharmD curricula; however, the payment mechanisms were not established to support significant numbers of non-dispensing positions. Almost 20 years later, this remains the fundamental challenge to broad-scale pharmacy practice transformation.

The current landscape is well known. Annual openings for new pharmacists entering the profession are projected to be 14,100 through 2028 , and in 2018 , there were 14,905 graduates from established pharmacy schools. ${ }^{2,3}$ In addition, nine new programs in candidate or pre-candidate accreditation status have yet to produce their first graduate. Thus, the number of newly minted pharmacists clearly will exceed the number of new job openings for the next several years. Oversupply may be corrected by reducing entering class size (ie, number of students accepted into PharmD programs), discontinuing some PharmD programs, and allowing the market to self-correct as potential pharmacy school applicants become aware of the limited employment opportunities available post-graduation and choose not to pursue pharmacy education.

Projected demand for pharmacists has finally hit zero overall net growth according to the US Bureau of Labor Statistics' employment projections for pharmacists for 2018 and $2028 .^{4}$ Although the majority of pharmacists 


\section{American Journal of Pharmaceutical Education 2020; 84 (10) Article 7889.}

continue to be employed in community pharmacy $(58 \%$ in 2018), recent events suggest the number of chain pharmacist jobs is waning, including layoffs by Walmart and store closures by Walgreens as part of "business transformation." ${ }^{, 56}$ Chain pharmacy corporations use a traditional business model of volume dispensing and fee for service, and are moving toward consolidation and automation to further increase efficiency, productivity, and shareholder profits. ${ }^{7}$

Although most pharmacists are still employed in community pharmacies for now, it is important and enlightening to look at data across the five broad sectors of pharmacist employment that cover about $96 \%$ of the jobs: the US Bureau of Labor Statistics categories are called retail trade, health care and social assistance, government, wholesale trade, and finance and insurance. Notably, growth is projected in all areas except for retail trade. The US Bureau of Labor Statistics projects an overall 5.1\% reduction in pharmacists in the retail trade sector by $2028 .{ }^{4} \mathrm{~A}$ closer look at the subcategories reveals the cause is primarily an $8.3 \%$ drop in health and personal care stores (from 134,700 to 123,500 ) and a $2.1 \%$ drop in food and beverage stores (from 24,000 to 23,500 ). This is a projected loss of almost 12,000 jobs over the next 10 years in these two subcategories. However, those big declines are slightly offset by growth in smaller retail trade subcategories, including a projected $47.1 \%$ increase in electronic shopping and mail-order houses (from 5,100 to $7,500)$.

The health care and social assistance sector is projected to increase by a modest $7.5 \%$ or 7,100 jobs overall (from 95,300 to 102,400), growing in most subcategories including general medical and surgical hospitals (by $2.5 \%$ or 1,900 jobs, from 76,300 to 78,200 ) outpatient care centers, including substance abuse (by $36.5 \%$ or 1,900 jobs, from 5,200 to 7,100), and offices of physicians (by $11.1 \%$ or 600 jobs, from 5,400 to 6,000$).{ }^{4}$ Other small and growing subcategories of jobs in health care and social assistance include those in psychiatric and substance abuse hospitals $(7.7 \%$ or 100 jobs, from 1,300 to 1,400$)$ and home health care services $(50.0 \%$ or 800 jobs, from 1,600 to 2,400 ). Jobs in the other three sectors mentioned previously are all projected to grow: finance and insurance $(15.6 \%$ or 700 jobs, from 4,500 to 5,200$)$, wholesale trade $(1.1 \%$ or 100 jobs, from 9,000 to 9,100$)$, and government $(1.0 \%$ or 100 jobs, from 9,700 to 9,800$)$. In future years, these gains are not going to be enough to offset the loss in retail positions without continued additional growth in emerging areas of the profession.

Job growth in the health care and social assistance sector is not exclusively for residency-trained pharmacists. The current capacity of PGY1 positions in $2019^{12}$ is barely enough for a quarter of the approximate 14,500 PharmD graduates. ${ }^{3}$

There is still an ongoing and perhaps increasing need for pharmacists resulting from shifts in the US population. According to the US Census Bureau, the population over the age of 65 years in 2008 was 37 million; in 2018, it was 52 million, and by 2060 , it is projected to be 95 million. ${ }^{8}$ Meanwhile, the younger population is not expanding at the same rate, with the $0-18$ years age range actually shrinking. While older people have more complex medical needs, the population shifts will likely result in a lack of available family caregivers and challenges with access to health care, particularly in rural and suburban areas. Only some $60 \%$ of the $65+$ years population are internet users, and older adults value interpersonal communication with health care professionals., ${ }^{9,10}$ This is where highly trained PharmD graduates who are skilled in medication therapy management can provide valuable expertise as part of the health care team. However, it may take innovative and entrepreneurial approaches to carve out new and profitable business models in this arena. ${ }^{11}$

Pharmacy schools must acknowledge that they can no longer rely on chain community pharmacies to employ the majority of their PharmD graduates, and as previously observed, transforming the profession to primarily valuebased roles will not happen overnight. Some have suggested creating a lower-tier dispensing pharmacist role to stave off the steady decline of available community pharmacy jobs, but the only foreseeable impact will be to drive down salaries across the profession. Others have suggested requiring postgraduate residency training as an additional layer of entry-level pharmacy practice, but as previously noted this is both unnecessary (because not all anticipated growth areas require residency training) and impossible (because the number of PGY1 positions accommodates only a quarter of PharmD graduates annually). Given the obvious trajectory toward oversupply of pharmacy graduates in the next several years, with $62,000+$ currently enrolled students expecting to enter the profession over the next four years, schools no longer have the luxury of promoting the role of a pharmacist as "the" career destination for the PharmD degree, and instead must prepare students to use the skills of their pharmacy education in many different roles.

To effectively advise students about the pharmacist job market and how to use their skills as medication experts in new ways, faculty advisors need to help students think more broadly about career opportunities. Faculty members are doing a disservice to their students if they promote PGY1 residency as the only or best pathway after graduation. Among the more than 14,000 graduates in 2019, nearly 6,000 participated in the PGY1 match and 


\section{American Journal of Pharmaceutical Education 2020; 84 (10) Article 7889.}

less than 4,000 matched, leaving several thousand students to begin a very competitive job search much later than their peers. ${ }^{12}$ Community pharmacy is no longer going to be the primary employer of graduates, nor is it the "back-up plan" for not matching for residency. Students need to be flexible in the jobs they pursue and be able to articulate what they can bring to the table. Skills such as communication, teamwork, problem solving, planning, and building effective relationships and networks are more important than ever as students seek out and secure nontraditional jobs. This diversification may ultimately have a positive impact on practice transformation, as other professions come to recognize the breadth and value of a PharmD education.

Advisors should encourage students to analyze job advertisements requiring applicants to have a sciencebased master's degree or doctorate, specifically those not requiring a PharmD or pharmacist licensure. Engage them in discussing why these less traditional jobs could be exciting career moves for new PharmD graduates. Students should practice advocating in cover letters and mock interviews as to how their education and breadth of experiences have prepared them for different positions, and how their unique perspective will enrich the organization's diversity of thought and function. Students should also find mentors that work outside of pharmacy for a more diverse perspective on career development and workforce issues. For example, a new PharmD graduate may not find a contractual position particularly appealing in terms of job security; however, a mentor with a broad professional background can describe how such positions can provide them with essential experience that forms the foundation of career mobility. Other important points for a mentor or advisor to emphasize are that a more interesting job may require the graduate to relocate to a different area of the country, accept a lower entry-level salary than anticipated, and perhaps spend more time performing administrative tasks than desired. The graduate's goal should be to accumulate a catalog of practical experience that will help build a fulfilling career.

While the pharmacy profession continues to make strides toward practice transformation, for the foreseeable future, schools and colleges must educate PharmD students on how to demonstrate the value of a pharmacy education in alternative careers and how a different career can be equally if not even more rewarding than the traditional pharmacist role they first envisioned.

\section{REFERENCES}

1. Knapp DA. Professionally determined need for pharmacy services in 2020. Am J Pharm Educ. 2002;66(4):421-429. http:// archive.ajpe.org/legacy/pdfs/aj660414.pdf. Accessed October 7, 2020 .

2. Employment Projections. Bureau of Labor Statistics, US Department of Labor. https://www.bls.gov/emp/tables/occupationalprojections-and-characteristics.htm. Accessed October 7, 2020.

3. 2018 Profile of Pharmacy Students, AACP Institutional Research, American Association of Colleges of Pharmacy. https://www.aacp. $\mathrm{org} / \mathrm{research} /$ student-applications-enrollments-and-degrees-conferred. Accessed October 7, 2020.

4. Occupational Outlook Handbook, Pharmacists, Employment by industry, occupation, and percent distribution, 2018 and projected 2028. Bureau of Labor Statistics, U.S. Department of Labor. https:// www.bls.gov/ooh/healthcare/pharmacists.htm\#tab-6. Accessed October 7, 2020.

5. Geske D. Walmart layoffs: retailer to eliminate up to 40 percent of its pharmacists. International Business Times. June 28, 2019. https:// www.ibtimes.com/walmart-layoffs-retailer-eliminate-40-percent-itspharmacists-2803631. Accessed October 7, 2020.

6. Japsen B. Walgreens isn't done closing drugstores in U.S. or abroad. Forbes. July 1, 2019. https://www.forbes.com/sites/ brucejapsen/2019/07/01/walgreens-isnt-done-closing-drugstores-inus-or-abroad/\#381f229e6492. Accessed October 7, 2020.

7. Why Automation is the Key to Your Chain Pharmacy's Success. McKesson blog. August 20, 2018. https://www.mckesson.com/blog/ why-automation-is-the-key-to-your-chain-pharmacys-success/.

Accessed October 7, 2020.

8. Eight demographic trends transforming America's older population. Population Reference Bureau. November 12, 2018. https://www.prb.org/eight-demographic-trends-transformingamericas-older-population/. Accessed October 7, 2020.

9. Older adults and technology use. Pew Research Center. Internet \& Technology. April 3, 2014. https://www.pewinternet.org/2014/04/03/ older-adults-and-technology-use/. Accessed October 7, 2020. 10. Effective communication in caring for older adults. National Institute on Aging. https://www.nia.nih.gov/health/effectivecommunication-caring-older-adults. Accessed October 7, 2020. 11. Cohen P. The 5 new pharmacy care models. December 16, 2018. https://www.managedhealthcareexecutive.com/pharmacy-bestpractices/5-new-pharmacy-care-models. Accessed October 7, 2020 .

12. National Matching Services Inc., American Society of HealthSystem Pharmacists (ASHP) Match Statistics. https://natmatch.com/ ashprmp/stats.html. Accessed October 7, 2020. 